\title{
Context-dependent effects of a single administration of mirtazapine on the expression of methamphetamine-induced conditioned place preference
}

\author{
Robin M. Voigt ${ }^{1,2 \dagger}$ and T. Celeste Napier ${ }^{1 *}$ \\ Department of Pharmacology, Center for Compulsive Behavior and Addiction, Rush University Medical Center, Chicago, IL, USA \\ 2 Department of Molecular Pharmacology and Therapeutics, Loyola University Chicago Medical Center, Maywood, IL, USA
}

Edited by:

Martine Ammassari-Teule, Consiglio

Nazionale delle Ricerche, Italy

\section{Reviewed by:}

Gregg Stanwood, Vanderbilt

University, USA

Pascale Gisquet-Verrier, Le Centre

National de la Recherche Scientifique,

France

Simona Cabib, Università Sapienza

Roma, Italy

\section{${ }^{*}$ Correspondence:}

T. Celeste Napier, Department of

Pharmacology, Rush University

Medical Center, Cohn Research

Building, 1735 West Harrison Street,

Suite \#424, Chicago, IL 60612, USA.

e-mail: celeste_napier@rush.edu

\section{${ }^{\dagger}$ Present address:}

Robin M. Voigt, Section of Digestive Diseases and Nutrition, Division of Gastroenterology, Department of Gastroenterology, Rush University Medical Center, Chicago, IL, USA.
Re-exposure to cues repeatedly associated with methamphetamine (Meth) can trigger Meth-seeking and relapse in the abstinent abuser. Weakening the conditioned Methassociated memory during cue re-exposure may provide a means for relapse-reduction pharmacotherapy. Accordingly, we sought to determine if the atypical antidepressant mirtazapine disrupted the persistence of Meth-induced conditioned place preference (CPP) when administered in conjunction with re-exposure to contextual conditioning cues, and if this effect was altered by Meth being present during cue re-exposure. First, we evaluated the effect of mirtazapine on the maintenance of Meth-induced CPP during re-exposure to either the saline- or Meth-paired chamber 12 days after conditioning. Meth-conditioned rats subsequently administered mirtazapine expressed CPP independent of re-exposure to the saline- or Meth-paired chamber; but the magnitude of CPP was significantly less for mirtazapine-treated rats re-exposed to the Meth-paired chamber. Next, we evaluated the effect of mirtazapine on a "reinforced re-exposure" to the Meth-paired context. Administration of mirtazapine vehicle and Meth, prior to re-exposure to the Meth-paired chamber did not disrupt the ability of rats to demonstrate CPP 15 days after conditioning; however, CPP was disrupted when rats were administered mirtazapine and Meth prior to re-exposure to the Meth-paired chamber. These results indicate that the capacity of mirtazapine to diminish Meth-induced CPP is promoted if mirtazapine treatment is coupled with Meth administration in the Meth-associated context and thus appears to be the consequence of disrupting processes necessary to reconsolidate CPP following activation of drug-associated memories.

Keywords: methamphetamine, psychostimulant, mirtazapine, addiction, conditioned place preference, associative learning

\section{INTRODUCTION}

Psychostimulant abuse, including the potent stimulant methamphetamine (Meth), is a serious public health problem worldwide. Exposure to cues associated with drug-use activates limbic brain regions in drug-addicted individuals (Childress et al., 1999, 2008) and these cues can elicit drug-craving and drug-seeking behaviors even after long periods of withdrawal (Ehrman et al., 1992; O'Brien et al., 1992; Hartz et al., 2001). Thus, diminishing the salience of Meth-associated cues may have significant therapeutic potential for relapse-reduction in the abstinent addict.

Associative learning between contextual cues (conditioned stimulus) and the rewarding effects of abused substances (unconditioned stimulus) can result in conditioned place preference (CPP), a behavior observed in humans (Childs and deWit, 2009) and rodents (O'Brien et al., 1998; Tzschentke, 1998, 2007). For associative memories, like CPP, to be expressed, the memory must be acquired, consolidated, and then recalled in order to be expressed (McGaugh, 2000). Re-exposure to salient drugassociated cues reactivates memories which must be reconsolidated to be retained. If reactivated memories are not successfully reconsolidated, the ability to subsequently recall the memory may be compromised (Tronson and Taylor, 2007). Supporting this concept, inhibiting reconsolidation via abrogating de novo protein synthesis in the brain (i.e., within the basal lateral amygdala) has been shown to reduce cue-induced cocaine seeking (Lee et al., 2006). Thus, reconsolidation is a particularly attractive therapeutic target for relapse-reduction by abstinent addicts where the associative memories formed between the rewarding effects of abused substances and contextual cues are thought to serve as powerful triggers to relapse. The current study advanced this idea by evaluating Meth-induced associative learning in rats using CPP expression as a behavioral output "window to the brain," and determining if systemic treatment intervention during reconsolidation could disrupt the persistent drug-associated memories.

The atypical antidepressant mirtazapine alters neurotransmission through a variety of receptors and signaling proteins; it acts as an antagonist at $\mathrm{H}_{1}, \alpha_{2}$ adrenergic, and $5-\mathrm{HT}_{2 \mathrm{~A} / 2 \mathrm{C}}$ serotonergic receptors and indirectly enhances adrenergic and $5-\mathrm{HT}_{1 \mathrm{~A}}-$ mediated neurotransmission via $\alpha_{2}$ adrenergic antagonism (Haddjeri et al., 1995, 1996, 1998a,b; de Boer, 1996; de Boer et al., 
1996). Studies from our laboratory have demonstrated the utility of mirtazapine to antagonize many consequences of repeated Meth administration including changes in neuronal activity (McDaid et al., 2007) and motor sensitization (McDaid et al., 2007), as well as and Meth-induced CPP established with a single pairing of Meth (Herrold et al., 2009). Most recently, we demonstrated that Meth-induced CPP established with three once-daily pairings of Meth (such as the one employed in the current study), was inhibited by 10 once-daily home cage injections of mirtazapine, but not by a single mirtazapine injection administered on the last day of the 10 once-daily treatment protocol (Voigt et al., 2011b). Thus, administration of mirtazapine in the neutral context of the home cage disrupted Meth-induced CPP only when given repeatedly, an outcome which may indicate that significant, enduring neuroplastic events were required in order for mirtazapine to inhibit memory maintenance. However, it is possible that such adaptations may not be required if the memory was made labile by re-exposing Meth-conditioned rats to contextual cues previously associated with Meth. The salience of context cues clearly regulates the brain state. For example, exposure to cues associated with abused drugs, including cocaine (Brown et al., 1992; Franklin and Druhan, 2000; Ciccocioppo et al., 2001; Zombeck et al., 2008) and Meth (Rhodes et al., 2005) increase neuronal activity in limbic brain regions, an effect which is specific to drug-paired cues (Brown et al., 1992; Franklin and Druhan, 2000; Ciccocioppo et al., 2001; Rhodes et al., 2005; Zombeck et al., 2008). The cue-elicited increases in neuronal activity are associated with enhancements in glutamatergic (Bell et al., 2000; Hotsenpiller et al., 2001) and dopaminergic (Lin et al., 2007) neurotransmission. As adrenergic and serotonergic systems modulate glutamate (Maura et al., 1988; Boehm, 1999) and dopamine (Kawahara et al., 2001; Di et al., 2008; Olvera-Cortes et al., 2008), we posited that mirtazapine may be able to indirectly disrupt neurotransmission that are evoked by salient cues and that such disruption may be sufficient to weaken the conditioned response memory bond. Thus, we sought to determine if a single injection of mirtazapine administered in conjunction with re-exposure to conditioned contextual cues (i.e., the saline- or Meth-paired chamber) during the postconditioning withdrawal period would alter performance in a subsequent CPP test. Moreover, after CPP has been acquired, a subsequent pairing of the unconditioned stimulus (Meth) with the conditioned stimulus (chamber context) should act to reinforce the CPP memory; however, it is not known how mirtazapine may influence this process. Therefore, we also determined if mirtazapine disrupted the maintenance of CPP when it was given along with Meth prior to re-exposing the rats to the Meth-paired chamber. Together these studies provide valuable new insights into mnemonic processes associated with Meth-induced CPP, as well as exploring the potential of mirtazapine as an anti-addiction therapy.

\section{MATERIALS AND METHODS ANIMALS}

Fifty-one male Sprague-Dawley rats (Harlan, Indianapolis, IN, USA) weighing 250-300 g at the start of the study were acclimated to the vivarium for at least 1 week prior to the onset of the experiment. Rats were housed in pairs in a climate-controlled environment on a 12-h light/dark cycle and allowed ad libitum access to food and water. Cage mates were given identical treatments. Housing facilities were accredited through the Association for Assessment and Accreditation of Laboratory Animal Care, and all experiments were carried out in accordance with the conditions set forth by the National Institutes of Health Guide for the Care and Use of Laboratory Animals (National Research Council, 1996) and with the approval of the Loyola University Institutional Animal Care and Use Committee.

\section{DRUGS}

(+)Methamphetamine $\mathrm{HCl}$ (Sigma, St. Louis, MO, USA) was dissolved in $0.9 \%$ sterile saline solution and the dose, $1 \mathrm{mg} / \mathrm{ml} / \mathrm{kg}$, was calculated as the salt. Meth vehicle was administered as $1 \mathrm{ml} / \mathrm{kg}$. Mirtazapine (1,2,3,4,10,14b-hexa-hydro-2-methyl-pyrazino [2,1a] pyrido [2,3-c] benzazepine; isolated from tablet by Plantex, Hackensack, NJ, USA, a division of Teva Pharmaceutical Industries, Ltd., North Wales, PA, USA) was dissolved in $\mathrm{HCl}$, then sterile water was added to the proper volume, with the final $\mathrm{pH}$ titrated to $\sim 6.3$ with $\mathrm{NaOH}$. Mirtazapine was administered as $5 \mathrm{mg} / \mathrm{ml} / \mathrm{kg}$. Mirtazapine vehicle was administered as $1 \mathrm{ml} / \mathrm{kg}$. All injections were given intraperitoneally (i.p.).

\section{APPARATUS FOR ASSESSING BEHAVIOR}

The test room was dimly lit (54-108 lx) with white noise (white noise generator, San Diego Instruments, San Diego, CA, USA) continuously present. The CPP apparatus $(63 \mathrm{~cm} \times 30 \mathrm{~cm} \times 30 \mathrm{~cm})$ consisted of three chambers divided by Plexiglas sliding doors (AccuScan Instruments, Inc., Columbus, OH, USA); two large conditioning chambers $(25 \mathrm{~cm} \times 30 \mathrm{~cm} \times 30 \mathrm{~cm})$ were separated by a small center chamber $(13 \mathrm{~cm} \times 30 \mathrm{~cm} \times 30 \mathrm{~cm})$. Each chamber had distinct visual and tactile cues. Chamber 1, vertical white stripes on walls and an overturned paint dish glued to the center of a patterned floor; Chamber 2, horizontal white stripes on walls and a grid floor; Center chamber, solid white walls and a smooth, slightly raised platform floor. Time spent in each chamber and motor activity was monitored via two sets of photobeams (24 horizontal and 12 vertical).

\section{CONDITIONED PLACE PREFERENCE}

The rats were transported from the housing room to the adjacent test room at least $30 \mathrm{~min}$ prior to the start of the experiment. Rats were given a 15 -min pre-test to verify that the box configuration did not produce a significant bias for either chamber (time spent in chamber $1,365 \pm 20 \mathrm{~s}$, time spent in chamber 2, $406 \pm 21 \mathrm{~s}$; $n=40$; paired $t$-test, $p>0.05$ ). However, individual rats tended to spend more time in one chamber or the other during the pretest, thus rats were Meth-paired in the chamber in which they spent the least amount of time during the pre-test. For 11 (of the 51 total) rats, pre-test data were lost due to computer error and these rats were randomly assigned to a chamber in which to receive Meth and saline. On days 1, 3, and 5 of conditioning, rats received a Meth injection and were immediately placed into the appropriate chamber (Meth-paired chamber) of the CPP box for $45 \mathrm{~min}$. On days 2 and 4 , rats received a saline injection and were immediately placed in the opposite chamber (saline-paired chamber) for $45 \mathrm{~min}$. This conditioning protocol reliably produces 
amphetamine- (Rademacher et al., 2006; Shen et al., 2006) and Meth- (Harper and Napier, 2005; Voigt and Napier, 2007)-induced CPP that is sensitive to pharmacological interventions (Harper and Napier, 2005; Shen et al., 2006; Voigt et al., 2011b).

For each experiment (described in detail below), rats were given the pre-treatment in the home cage $30 \mathrm{~min}$ prior to the treatment, and immediately re-exposed to either the Meth-paired or saline-paired chamber for $45 \mathrm{~min}$. Rats were tested for preference 3 days later (on day 20) to allow mirtazapine to be eliminated from the system prior to testing. To do so, rats were placed into the center chamber and sliding doors immediately removed allowing free access to the entire CPP box. The test session lasted $30 \mathrm{~min}$ and time spent in each chamber was evaluated to determine preference.

\section{Experiment 1, development and persistence of Meth-induced CPP}

Rats $(n=8)$ were conditioned with Meth and tested for preference on day 8 to verify the development of CPP (Figure 1A). On day 17 , these same rats received a pre-treatment of mirtazapine vehicle followed by a Meth vehicle treatment, were re-exposed to the saline-paired chamber and subsequently tested for CPP on day 20. This experimental design enabled us to verify that repeated CPP testing or re-exposure to non-significant (i.e., saline-paired cues) did not disrupt the ability of rats to retain and demonstrate a preference for the Meth-paired chamber.

\section{Experiment 2, influence of chamber association on mirtazapine-induced effects}

On day 17 , Meth-conditioned rats $(n=17)$ received either $(1)$ mirtazapine pre-treatment followed by a treatment of Meth vehicle and re-exposed to the saline-paired chamber $(n=11)$ or $(2) \mathrm{mir}-$ tazapine pre-treatment followed by Meth vehicle treatment $(n=6)$ and re-exposed to the Meth-paired chamber (Figure 1B). All rats were tested for place preference on day 20. This experimental design enabled us to determine the influence of saline- or Methpaired cues on mirtazapine-induced effects, i.e. how mirtazapine influenced reconsolidation of Meth-induced CPP following re-exposure to saline- or Meth-induced cues.

\begin{tabular}{|c|c|c|c|c|}
\hline Pre-Test & Conditioning & $\begin{array}{l}\text { CPP } \\
\text { Test }\end{array}$ & Re-exposure & $\begin{array}{l}\text { CPP } \\
\text { Test }\end{array}$ \\
\hline | & 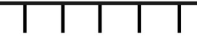 & $T$ & $\mathrm{~T}$ & 7 \\
\hline Day: 0 & $\begin{array}{lllll}1 & 2 & 3 & 4 & 5\end{array}$ & 8 & 17 & 20 \\
\hline Treatment: $\varnothing$ & $M S M S M$ & $\varnothing$ & Various & $\varnothing$ \\
\hline Pre-Test & Conditioning & & Re-exposure & $\begin{array}{l}\text { CPP } \\
\text { Test }\end{array}$ \\
\hline Г & $\begin{array}{llllll} & 1 & 1 & 1\end{array}$ & & T & 7 \\
\hline Day: 0 & 12345 & & 17 & 20 \\
\hline Treatment: $\varnothing$ & $M S M S M$ & & Various & $\varnothing$ \\
\hline \multicolumn{5}{|c|}{$\begin{array}{l}\text { FIGURE } 1 \text { | Experimental timelines. M, methamphetamine }(1 \mathrm{mg} / \mathrm{kg}) \text {; } \mathrm{S} \text {, } \\
\text { saline }(1 \mathrm{ml} / \mathrm{kg}) ; \varnothing \text {, no drug. (A) Timeline for Experiment } 1 \text {. (B) Timeline for } \\
\text { Experiments } 2 \text { and } 3 \text {. }\end{array}$} \\
\hline
\end{tabular}

\section{Experiment 3, the ability of mirtazapine to alter reinforced re-exposure}

On day 17 , Meth-conditioned rats $(n=21)$ were administered (1) mirtazapine vehicle pre-treatment followed by Meth treatment and re-exposed to the Meth-paired chamber $(n=14)$ or (2) mirtazapine pre-treatment followed by Meth treatment prior to re-exposure to the Meth-paired chamber $(n=7)$ and the rats were tested for CPP on day 20 (Figure 1B). This experimental design allowed us to determine how a reinforced re-exposure to the Meth-paired chamber would affect mirtazapine effects on the reconsolidation of Meth-induced CPP.

\section{STATISTICAL ANALYSIS}

Experiment 1 (Figure 2): A two-way repeated measures ANOVA was used to evaluate CPP across multiple CPP tests with the factor of chamber (saline-paired vs. Meth-paired) and the repeated factor of test. Experiments 2 and 3 (Figures 3 and 4): A mixed factor ANOVA was employed with the within subjects factor of chamber and the between subjects factor of treatment. For all experiments, a post hoc Newman-Keuls test was used to identify between chamber differences $(\alpha=0.05)$; and significant preference was indicated as a significantly greater amount of time spent in the Meth-paired chamber compared to the time spent in the saline-paired chamber. Time spent in the center chamber was not included in the statistical analysis. Data are presented as mean \pm SEM. Statistical outliers were determined as those rats that spent greater than 2 SD above or below the mean time spent in any chamber; four rats out of the total 50 were excluded as outliers.

\section{RESULTS}

\section{EXPERIMENT 1: DEVELOPMENT AND PERSISTENCE OF METH-INDUCED} CPP

The results revealed that three pairings with Meth was sufficient to induce a preference that was expressed 3 days after conditioning (Figure 2, Day $8 \mathrm{CPP}$ Test, left set of bar graphs). Furthermore, this preference was not disrupted by experimental procedures conducted on day 17 or due to repeated CPP testing (Figure 2, right set of bar graphs). That is, when rats $(n=8)$ were administered mirtazapine vehicle + Meth vehicle, a two-way repeated measures ANOVA (test $\times$ chamber) revealed a significant effect of chamber $\left[F_{(1,14)}=39.060, p<0.0001\right]$ but no effect of test $\left[F_{(1,14)}=0.092, p=0.766\right]$ or test-chamber interaction $\left[F_{(1,14)}=0.035, p=0.854\right]$. Post hoc Newman-Keuls revealed time spent in the Meth-paired chamber was significantly greater than time spent in the saline-paired chamber for both tests $(p<0.01$; Figure 2). Hence, the preference that is evident 3 days after conditioning was not altered by repeated testing, experimental procedures on day 17 , or by the 15 -day withdrawal period.

\section{EXPERIMENT 2: MIRTAZAPINE AND RE-EXPOSURE TO CONDITIONING CUES}

Meth-conditioned rats were used to evaluate the effect of mirtazapine on mnemonic processes engaged during re-exposure to either the saline- or Meth-paired chamber on day 17. Analysis of CPP test data revealed a significant effect of chamber $\left[F_{(1,30)}=46.530, p<0.0001\right]$ and a treatment-chamber interaction $\left[F_{(1,30)}=10.439, p=0.003\right]$ with no effect of treatment 
$\left[F_{(1,30)}=0.283, p=0.599\right]$. This demonstrates that rats who received mirtazapine + Meth vehicle treatments on day 17 in either the saline- or Meth-paired chamber, maintain CPP (Figure 3; re-exposed to the saline-paired chamber, left set of bar graphs $(n=11)$, post hoc Newman-Keuls, $p<0.01$; re-exposed to the Meth-paired chamber, shown in right set of bar graphs $(n=6)$, post hoc Newman-Keuls, $p<0.05$ ). Even so, time spent in the Meth-paired chamber was significantly less after re-exposure to the Meth-paired chamber than after re-exposure to the salinepaired chamber (Figure 3, between treatment groups, post hoc Newman-Keuls, $p<0.05)$. These results indicate that context is a significant factor in the ability of mirtazapine to alter the processes necessary to subsequently express Meth-induced CPP.

\section{EXPERIMENT 3: MIRTAZAPINE AND REINFORCED RE-EXPOSURE TO THE METH-PAIRED CHAMBER}

This experiment determined the ability of mirtazapine to modulate the maintenance of Meth-induced CPP when administered prior to a "reinforced exposure" to the Meth-paired chamber. Reinforcement was accomplished by administering Meth $(1 \mathrm{mg} / \mathrm{kg})$

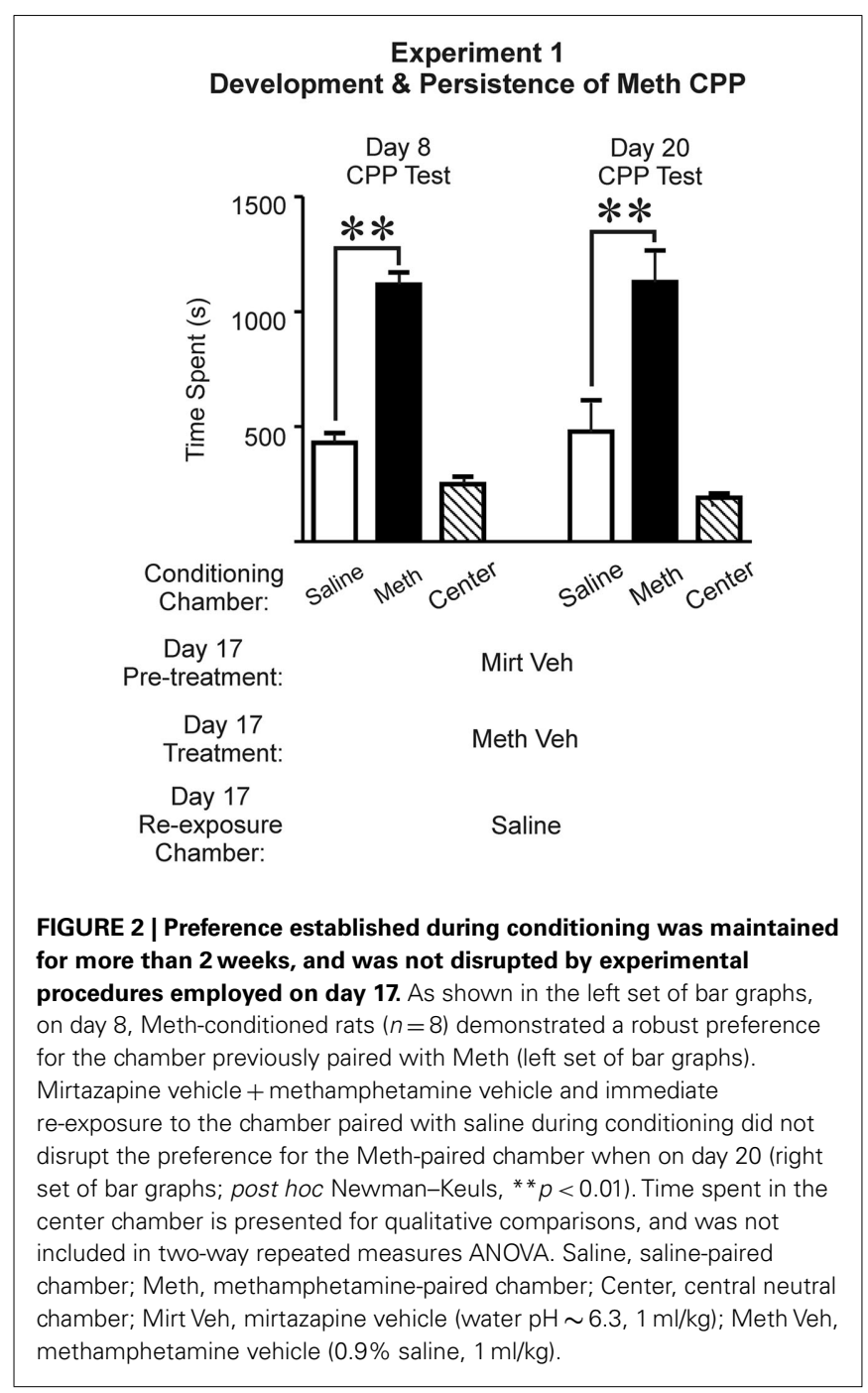

30 min after mirtazapine (or its vehicle) and immediately reexposing the rats to the Meth-paired chamber. A two-way ANOVA of CPP test data revealed a significant treatment-chamber interaction $\left[F_{(1,38)}=18.824, p=0.0001\right]$ with non-significance for the effects of treatment $\left[F_{(1,38)}=0.001, p=0.981\right]$ or chamber $\left[F_{(1,38)}=2.895, p=0.097\right]$. Post hoc Newman-Keuls test revealed that administration of mirtazapine vehicle + Meth prior to reexposure to the Meth-paired chamber did not inhibit the ability of rats to express a preference (Figure 4, left set of bar graphs $(n=14)$, $p<0.01)$. In contrast, rats that received mirtazapine + Meth prior to re-exposure to the Meth-paired chamber, did not demonstrate a preference for the Meth context during the CPP test (Figure 4, right set of bar graphs $(n=7)$, post hoc Newman-Keuls, $p>0.05)$. A between groups comparison showed that the magnitude of time spent in the Meth-paired chamber was significantly decreased after mirtazapine + Meth compared to vehicle + Meth; the decrease in time spent in the Meth-paired chamber was accompanied by an increase in time spent in the saline-paired chamber (Figure 4, post hoc Newman-Keuls, $p<0.05)$.

These data demonstrate the unique ability of mirtazapine administered in conjunction with re-exposure to the Meth-paired chamber to diminish the expression of the previously established

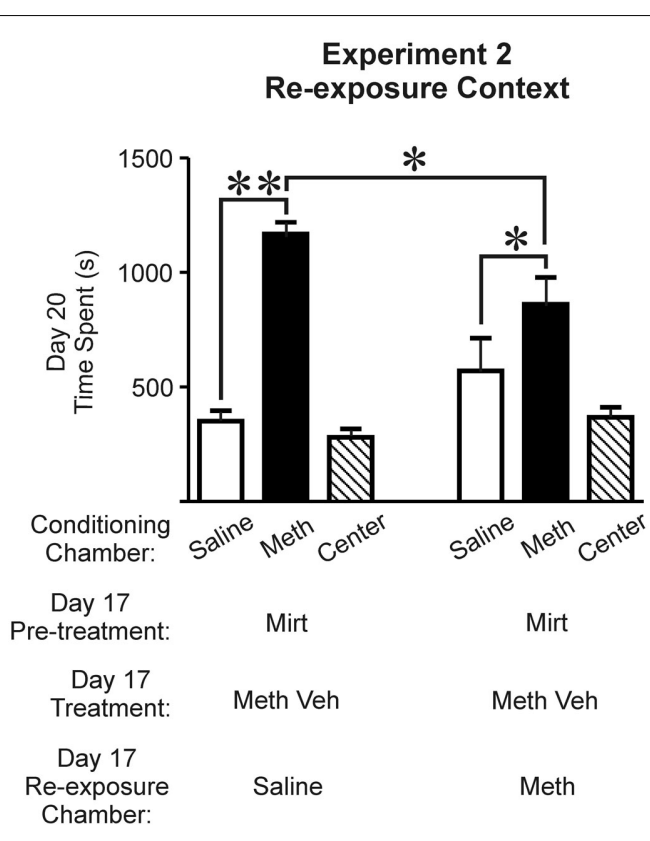

FIGURE 3 | Mirtazapine administered prior to re-exposure to the Meth-paired chamber, but not the saline-paired chamber, on day 17 inhibited the expression of Meth-induced CPP on day 20. Rats re-exposed to the saline-paired chamber ( $n=11$; left set of bar graphs) or to the Meth-paired chamber ( $n=6$; right set of bar graphs) both expressed a preference for the Meth-paired chamber (post hoc Newman-Keuls; $\left.{ }^{*} p<0.05,{ }^{*} p<0.01\right)$. However, the magnitude of the preference for the Meth-paired chamber was significantly less in rats re-exposed to the Meth-paired chamber (post hoc Newman-Keuls, $p<0.05$ ). Time spent in the center chamber is presented for qualitative comparisons, and was not included for statistical analysis. Saline, saline-paired chamber; Meth, methamphetamine-paired chamber; Center, central neutral chamber; Mirt, mirtazapine $(5 \mathrm{mg} / \mathrm{kg})$; Meth Veh, methamphetamine vehicle $(0.9 \%$ saline). 


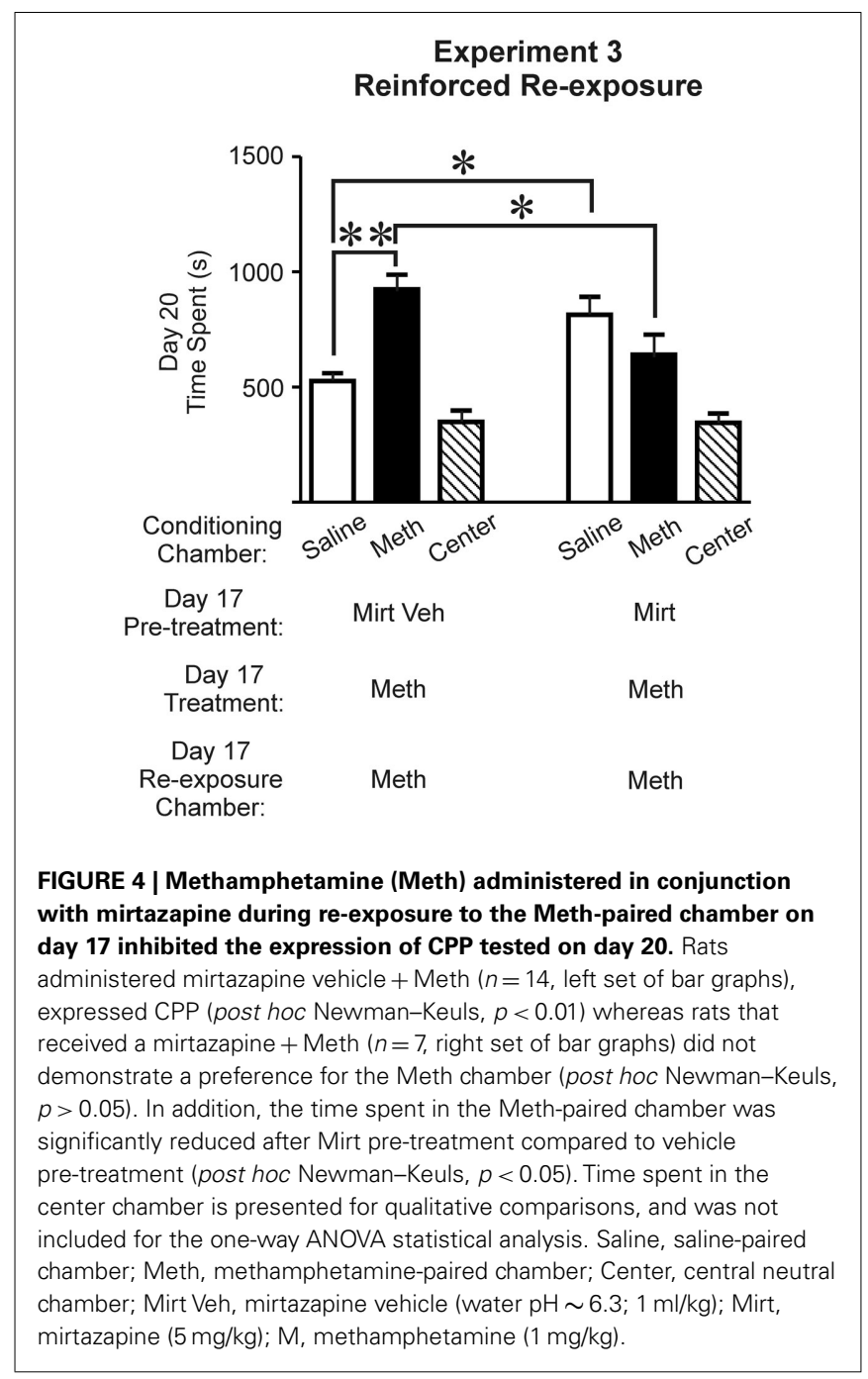

Meth-induced preference both in the absence (Figure 3) and the presence of the unconditioned stimulus, Meth (Figure 4).

\section{DISCUSSION}

Our results suggest that mirtazapine disrupts reconsolidation of CPP upon re-exposure to salient Meth-paired cues (Experiment 2); an effect which was more robust when the re-exposure was coupled with the unconditioned stimulus Meth (Experiment 3). This effect is highly significant because it indicates that Meth contributes to the labile state induced by contextual cues to promote the pharmacological actions of mirtazapine and demonstrates that activation of brain regions by reexposure to salient cues and by Meth administration synergize to render the brain susceptible to influence by mirtazapine. Such effects were not obtained when mirtazapine was administered either in the home cage (Voigt et al., 2011b) or in conjunction with re-exposure to the saline-paired context (Experiment 2), underscoring the importance of the Meth-paired context in the ability of mirtazapine to disrupt Meth-associated memories.
The contextual dependence of mirtazapine (i.e., Meth-paired chamber vs. the saline-paired chamber effects) points to the vulnerability of the brain during the time when it is recognizing the reward-associated context. Furthermore, the robust disruption of CPP that occurred when Meth-paired cues were combined with Meth administration indicates that presentation of salient cues synergizes with Meth to enhance memory reactivation, rendering the memory more sensitive to disruption by mirtazapine. This synergistic effect is likely the consequence of neurotransmitter systems and brain circuits commonly engaged by re-exposure to salient drug-associated cues and Meth. In drug-addicted humans, cues associated with an abused substance activate limbic brain regions (measured with fMRI or PET; Childress et al., 1999, 2008; Kilts et al., 2001, 2004). In rats, Fos expression, a marker for neuronal activity (Sagar et al., 1988; Dragunow and Faull, 1989; Morgan and Curran, 1989), is increased in limbic brain regions after reexposure to cues associated with cocaine (Brown et al., 1992; Franklin and Druhan, 2000; Ciccocioppo et al., 2001; Zombeck et al., 2008) and Meth (Rhodes et al., 2005); such neuronal activity does not occur when rats are re-exposed to non-drug-paired cues (Brown et al., 1992; Franklin and Druhan, 2000; Ciccocioppo et al., 2001; Hotsenpiller et al., 2001; Hotsenpiller and Wolf, 2002; Rebec and Sun, 2005; Rhodes et al., 2005; Zombeck et al., 2008). In rodents, many of the same regions which exhibit an increase in Fos expression after exposure to cocaine-paired cues, also demonstrate an increase in Fos expression after acute cocaine administration (e.g., cingulate cortex, claustrum, and amygdala). Additionally, repeated, intermittent administration of a psychostimulant (e.g., Meth) renders the brain more sensitive to subsequent druginjections (Pierce and Kalivas, 1997; Sax and Strakowski, 2001; McDaid et al., 2006, 2007). Thus, the activated brain state (i.e., cue-induced and/or Meth-induced) appears to provide a unique substrate that allows mirtazapine to weaken the Meth memory. The importance of the Meth-paired chamber is underscored by our previous work which demonstrated that a single injection of mirtazapine given in the neutral context of the home cage, on the same day as in the current protocol (i.e., 12 days after conditioning), was unable to inhibit the expression of Meth-induced CPP (Voigt et al., 2011b). The similar outcomes of our previously published work (Voigt et al., 2011b) and the results obtained during re-exposure to the saline-paired context would be expected if similar non-activated brain states were produced when rats remained in the home cage and when re-exposed to the saline-paired context.

In the current treatment protocol is difficult to discern between mirtazapine effects on maintenance, consolidation, and reconsolidation of the CPP memory. However, the results are likely not due an inhibition of memory maintenance independent of reexposure to conditioning the cues as we have previously observed that a single administration of mirtazapine given in the home cage on day 17 did not inhibit the maintenance of Meth-induced CPP (Voigt et al., 2011b). Thus, mirtazapine is likely influencing consolidation and/or reconsolidation of processes that relate to salient drug-paired contextual memories. One possible mechanism by which mirtazapine may have disrupted CPP is via facilitating the extinction of CPP by enhancing consolidation of a new mnemonic event (i.e., that the Meth-paired chamber was uncoupled from the rewarding effects of Meth). Non-reinforced 
exposure to a previously drug-paired context can result in extinction and may, in part, explain the outcomes of Experiment 2 (i.e., a non-reinforced re-exposure). However, typically it takes multiple non-reinforced exposures to extinguish a CPP memory (Voigt et al., 2011a); therefore, it is not likely that extinction processes are responsible for the outcome in Experiment 2. Furthermore, Experiment 3 was a reinforced exposure which would not be expected to result in extinction. Another interpretation of these data is that mirtazapine is disrupting Meth-induced CPP due to an intrinsic aversive property of mirtazapine. If so, administration of mirtazapine prior to re-exposure to the Meth-paired chamber would be expected to produce a dysphoric effect to override the previous Meth-induced preference. While very high doses of mirtazapine have been reported to produce dysphoria (Bhanji et al., 2002), the mirtazapine dose used in our experiments would not be expected to produce either preference or aversion (Kang et al., 2008). Thus, it seems unlikely that this explanation is responsible for the outcomes observed in our experiments.

A probable explanation for the observed effects of mirtazapine is via inhibiting CPP memory reconsolidation. Re-exposure to cues triggers memory recall, making the memory labile and sensitive to disruption; if the memory is not successfully reconsolidated the ability to subsequently recall the memory may be compromised (Tronson and Taylor, 2007). Targeting reconsolidation as a means to reduce drug-associated behaviors has been reported; protein synthesis inhibitors disrupt the reconsolidation of cocaine (Valjent et al., 2006) and morphine-induced CPP (Milekic et al., 2006), inhibition of the ERK kinase MEK after re-exposure to conditioning cues inhibits memory reconsolidation (Miller and Marshall, 2005), and cue-induced cocaine seeking is successfully inhibited by disrupting memory reconsolidation (Dudai, 2006). The present study extends this literature by showing that a mirtazapine negatively impacted the CPP memory when combined with re-exposure to the Methassociated chamber (but not the saline-paired chamber). The receptor and downstream targets of mirtazapine are known to modify memory reconsolidation (as well as consolidation); the mechanisms of which overlap with reconsolidation (Dudai, 2006). For example, consolidation/reconsolidation are promoted by posttraining brain infusions of an $\mathrm{H}_{1}$ receptor antagonists (Hasenohrl et al., 2001; Eidi et al., 2003) and $\alpha_{2}$ antagonists (Ferry and

\section{REFERENCES}

Albert, P. R., and Tiberi, M. (2001). Receptor signaling and structure: insights from serotonin-1 receptors. Trends Endocrinol. Metab. 12, 453-460.

Arnsten, A. F., Ramos, B. P., Birnbaum, S. G., and Taylor, J. R. (2005). Protein kinase A as a therapeutic target for memory disorders: rationale and challenges. Trends Mol. Med. 11, 121-128.

Bell, K., Duffy, P., and Kalivas, P. W. (2000). Context-specific enhancement of glutamate transmission by cocaine. Neuropsychopharmacology 23, 335-344.
Bhanji, N. H., Margolese, H. C., SaintLaurent, M., and Chouinard, G. (2002). Dysphoric mania induced by high-dose mirtazapine: a case for "norepinephrine syndrome?" Int. Clin. Psychopharmacol. 17, 319-322.

Boehm, S. (1999). Presynaptic alpha2adrenoceptors control excitatory, but not inhibitory, transmission at rat hippocampal synapses. J. Physiol. (Lond.) 519(Pt 2), 439-449.

Bourtchouladze, R., Abel, T., Berman, N., Gordon, R., Lapidus, K., and Kandel, E. R. (1998). Different training procedures recruit either one or two critical periods for contextual memory consolidation,

McGaugh, 2008), and post-training systemic administration of selective serotonin reuptake inhibitors (Meneses, 2007b), 5- $\mathrm{HT}_{1 \mathrm{~A}}$ receptor agonists (Meneses and Hong, 1999; Meneses, 2007a; Meneses and Perez-Garcia, 2007), and an $\alpha_{2}$ antagonist (Haapalinna et al., 1998). Consolidation/reconsolidation can also be inhibited by antagonism of $\mathrm{H}_{1}$ receptors (Dai et al., 2007; Zlomuzica et al., 2009) as does $5-\mathrm{HT}_{1 \mathrm{~A}}$ receptor activation (Eriksson et al., 2008). Downstream consequences of mirtazapine include negative regulation of adenylate cyclase and consequently PKA via 5-HT HA $_{\text {A }}$ (Devivo and Maayani, 1985; Schoeffter and Hoyer, 1988; Albert and Tiberi, 2001; Lanfumey and Hamon, 2004) and $\alpha_{2}$ adrenergic receptors (Jakobs and Schultz, 1982; Arnsten et al., 2005). PKA is critical for memory consolidation (Bourtchouladze et al., 1998; Vianna et al., 2000; Quevedo et al., 2004; Isiegas et al., 2006) and reconsolidation (Micheau and Riedel, 1999); providing another mechanism by which mirtazapine may have mediated the behavioral effects observed in the current study. Thus, there are several mechanisms by which mirtazapine may inhibit the reconsolidation of the Meth-induced CPP memory. Whatever the mechanism, our results show that an activated brain state makes the process more vulnerable to mirtazapine.

Clinical studies support the use of mirtazapine as a pharmacotherapy for Meth abuse. Mirtazapine reduces the severity of withdrawal symptoms in human abusers of amphetamine (Kongsakon et al., 2005) and Meth (McGregor et al., 2008; Colfax et al., 2011) and appears to sustain abstinence from opiate and cocaine use (Rafeyan and Napier, 2008). Mirtazapine also is reported to reduce cocaine craving (Zueco Perez, 2002). Other clinical evaluations failed to demonstrate favorable clinical outcomes with mirtazapine therapy (Cruickshank et al., 2008; Shoptaw et al., 2009). We propose that the value of mirtazapine therapy may be better realized by considering the role of drug-associated cues during a time of relapse.

\section{ACKNOWLEDGMENTS}

Work supported by USPHSGs DA015760 to T. Celeste Napier, and DA021475 to Robin M. Voigt and T. Celeste Napier. The authors thank Laura K. Harper for technical assistance and Amanda L. Mickiewicz and Steven M. Graves for their thoughtful discussions and comments in the preparation of this manuscript.

each of which requires protein synthesis and PKA. Learn. Mem. 5, 365-374.

Brown, E. E., Robertson, G. S., and Fibiger, H. C. (1992). Evidence for conditional neuronal activation following exposure to a cocaine-paired environment: role of forebrain limbic structures. J. Neurosci. 12, 4112. Childress, A. R., Ehrman, R. N., Wang, Z., Li, Y., Sciortino, N., Hakun, J., Jens, W., Suh, J., Listerud, J., Marquez, K., Franklin, T., Langleben, D., Detre, J., and O'Brien, C. P. (2008). Prelude to passion: limbic activation by "unseen" drug and sexual cues. PLoS ONE 3, e1506. doi:10.1371/journal.pone.0001506
Childress, A. R., Mozley, P. D., McElgin, W., Fitzgerald, J., Reivich, M., and O'Brien, C. P. (1999). Limbic activation during cue-induced cocaine craving. Am. J. Psychiatry 156, 11-18.

Childs, E., and deWit, H. (2009). Amphetamine-induced place preference in humans. Biol. Psychiatry 65, 900-904.

Ciccocioppo, R., Sanna, P. P., and Weiss, F. (2001). Cocaine-predictive stimulus induces drug-seeking behavior and neural activation in limbic brain regions after multiple months of abstinence: reversal by $\mathrm{D}(1)$ antagonists. Proc. Natl. Acad. Sci. U.S.A. 98, 1976-1981. 
Colfax, G. N., Santos, G. M., Das, M., Santos, D. M., Matheson, T., Gasper, J., Shoptaw, S., and Vittinghoff, E. (2011). Mirtazapine to reduce methamphetamine use: a randomized controlled trial. Arch. Gen. Psychiatry 68, 1168-1175.

Cruickshank, C. C., Montebello, M. E., Dyer, K. R., Quigley, A., Blaszczyk, J., Tomkins, S., and Shand, D. (2008). A placebo-controlled trial of mirtazapine for the management of methamphetamine withdrawal. Drug Alcohol Rev. 27, 326-333.

Dai, H., Kaneko, K., Kato, H., Fujii, S., Jing, Y., Xu, A., Sakurai, E., Kato, M., Okamura, N., Kuramasu, A., and Yanai, K. (2007). Selective cognitive dysfunction in mice lacking histamine $\mathrm{H} 1$ and $\mathrm{H} 2$ receptors. Neurosci. Res. 57, 306-313.

de Boer, T. H. (1996). The pharmacologic profile of mirtazapine. J. Clin. Psychiatry 57(Suppl. 4), 19-25.

de Boer, T. H., Nefkens, F., van Helvoirt, A., and Van Delft, A. M. (1996). Differences in modulation of noradrenergic and serotonergic transmission by the alpha-2 adrenoceptor antagonists, mirtazapine, mianserin and idazoxan. J. Pharmacol. Exp. Ther. 277, 852-860.

Devivo, M., and Maayani, S. (1985). Inhibition of forskolin-stimulated adenylate cyclase activity by $5-\mathrm{HT}$ receptor agonists. Eur. J. Pharmacol. 119, 231-234.

Di, G. G., Di, M. V., Pierucci, M., and Esposito, E. (2008). Serotonindopamine interaction: electrophysiological evidence. Prog. Brain Res. 172, 45-71.

Dragunow, M., and Faull, R. (1989). The use of c-fos as a metabolic marker in neuronal pathway tracing. J Neurosci. Methods 29, 261-265.

Dudai, Y. (2006). Reconsolidation: the advantage of being refocused. Curr. Opin. Neurobiol. 16, 174-178.

Ehrman, R. N., Robbins, S. J., Childress, A. R., and O'Brien, C. P. (1992). Conditioned responses to cocaine-related stimuli in cocaine abuse patients. Psychopharmacology (Berl.) 107, 523-529.

Eidi, M., Zarrindast, M. R., Eidi, A., Oryan, S., and Parivar, K. (2003). Effects of histamine and cholinergic systems on memory retention of passive avoidance learning in rats. Eur. J. Pharmacol. 465, 91-96.

Eriksson, T. M., Golkar, A., Ekstrom, J. C., Svenningsson, P., and Ogren, S. O. (2008). 5-HT7 receptor stimulation by $8-\mathrm{OH}$-DPAT counteracts the impairing effect of 5-HT(1A) receptor stimulation on contextual learning in mice. Eur. J. Pharmacol. 596, 107-110.

Ferry, B., and McGaugh, J. L. (2008). Involvement of basolateral amygdala alpha2-adrenoceptors in modulating consolidation of inhibitory avoidance memory. Learn. Mem. 15, 238-243.

Franklin, T. R., and Druhan, J. P. (2000). Expression of Fos-related antigens in the nucleus accumbens and associated regions following exposure to a cocaine-paired environment. Eur. J. Neurosci. 12, 2097-2106

Haapalinna, A., Sirvio, J., and Lammintausta, R. (1998). Facilitation of cognitive functions by a specific alpha2-adrenoceptor antagonist, atipamezole. Eur. J. Pharmacol. 347, 29-40.

Haddjeri, N., Blier, P., and de, M. C. (1995). Noradrenergic modulation of central serotonergic neurotransmission: acute and longterm actions of mirtazapine. Int. Clin. Psychopharmacol. 10(Suppl.4), 11-17.

Haddjeri, N., Blier, P., and de, M. C. (1996). Effect of the alpha-2 adrenoceptor antagonist mirtazapine on the 5-hydroxytryptamine system in the rat brain. J. Pharmacol. Exp. Ther. 277, 861-871.

Haddjeri, N., Blier, P., and De Montigny, C. (1998a). Acute and longterm actions of the antidepressant drug mirtazapine on central 5-HT neurotransmission. J. Affect. Disord. 51, 255-266.

Haddjeri, N., Blier, P., and De Montigny, C. (1998b). Long-term antidepressant treatments result in a tonic activation of forebrain 5-HT1A receptors. J. Neurosci. 18, 10150-10156.

Harper, L. K., and Napier, T. C. (2005). Treatment with the antidepressant mirtazapine negates conditioned place preference and motor sensitization established by methamphetamine. Abstr. Soc. Neurosci. 31, 75.9.

Hartz, D. T., Frederick-Osborne, S. L., and Galloway, G. P. (2001). Craving predicts use during treatment for methamphetamine dependence: a prospective, repeated-measures, within-subject analysis. Drug Alcohol Depend. 63, 269-276.

Hasenohrl, R. U., Kuhlen, A., Frisch, C., Galosi, R., Brandao, M. L., and Huston, J. P. (2001). Comparison of intra-accumbens injection of histamine with histamine H1-receptor antagonist chlorpheniramine in effects on reinforcement and memory parameters. Behav. Brain Res. 124, 203-211.

Herrold, A. A., Shen, F., Graham, M. P., Harper, L. K., Specio, S. E., Tedford,
C. E., and Napier, T. C. (2009). Mirtazapine treatment after conditioning with methamphetamine alters subsequent expression of place preference. Drug Alcohol Depend. 99, 231-239.

Hotsenpiller, G., Giorgetti, M., and Wolf, M. E. (2001). Alterations in behaviour and glutamate transmission following presentation of stimuli previously associated with cocaine exposure. Eur. J. Neurosci. $14,1843-1855$.

Hotsenpiller, G., and Wolf, M. E. (2002). Extracellular glutamate levels in prefrontal cortex during the expression of associative responses to cocaine related stimuli. Neuropharmacology 43, 1218-1229.

Isiegas, C., Park, A., Kandel, E. R. Abel, T., and Lattal, K. M. (2006). Transgenic inhibition of neuronal protein kinase A activity facilitates fear extinction. J. Neurosci. 26 , 12700-12707.

Jakobs, K. H., and Schultz, G. (1982). Signal transformation involving alpha-adrenoceptors. J. Cardiovasc. Pharmacol. 4(Suppl. 1), S63-S67.

Kang, L., Wang, D., Li, B., Hu, M., Zhang, P., and Li, J. (2008). Mirtazapine, a noradrenergic and specific serotonergic antidepressant, attenuates morphine dependence and withdrawal in Sprague-Dawley rats. Am. J. Drug Alcohol Abuse 34, 541-552.

Kawahara, H., Kawahara, Y., and Westerink, B. H. (2001). The noradrenaline-dopamine interaction in the rat medial prefrontal cortex studied by multi-probe microdialysis. Eur. J. Pharmacol. 418, 177-186

Kilts, C. D., Gross, R. E., Ely, T. D., and Drexler, K. P. (2004). The neural correlates of cue-induced craving in cocaine-dependent women. Am. J. Psychiatry 161, 233-241.

Kilts, C. D., Schweitzer, J. B., Quinn, C. K., Gross, R. E., Faber, T. L., Muhammad, F., Ely, T. D., Hoffman, J. M., and Drexler, K. P. (2001) Neural activity related to drug craving in cocaine addiction. Arch. Gen. Psychiatry 58, 334-341.

Kongsakon, R., Papadopoulos, K. I., and Saguansiritham, R. (2005). Mirtazapine in amphetamine detoxification: a placebo-controlled pilot study. Int Clin. Psychopharmacol. 20, 253-256. Lanfumey, L., and Hamon, M. (2004). 5-HT1 receptors. Curr. Drug Targets CNS Neurol. Disord. 3, 1-10.

Lee, J. L., Milton, A. L., and Everitt, B. J. (2006). Cue-induced cocaine seeking and relapse are reduced by disruption of drug memory reconsolidation. J. Neurosci. 26, 5881-5887.
Lin, S. K., Pan, W. H., and Yeh, P. H. (2007). Prefrontal dopamine efflux during exposure to drug-associated contextual cues in rats with prior repeated methamphetamine. Brain Res. Bull. 71, 365-371.

Maura, G., Roccatagliata, E., Ulivi, M., and Raiteri, M. (1988). Serotoninglutamate interaction in rat cerebellum: involvement of 5-HT1 and 5-HT2 receptors. Eur. J. Pharmacol. 145, 31-38.

McDaid, J., Graham, M. P., and Napier, T. C. (2006). Methamphetamineinduced sensitization differentially alters pCREB and $\triangle$ FosB throughtout the limbic circuit of the mammalian brain. Mol. Pharmacol. 70, 2064-2074.

McDaid, J., Tedford, C. E., Mackie, A. R., Dallimore, J. E., Mickiewicz, A. L., Shen, F., Angle, J. M., and Napier, T. C. (2007). Nullifying drug-induced sensitization: behavioral and electrophysiological evaluations of dopaminergic and serotonergic ligands in methamphetaminesensitized rats. Drug Alcohol Depend. 86, 55-66.

McGaugh, J. L. (2000). Memory - a century of consolidation. Science 287 248-251.

McGregor, C., Srisurapanont, M., Mitchell, A., Wickes, W., and White, J. M. (2008). Symptoms and sleep patterns during inpatient treatment of methamphetamine withdrawal: a comparison of mirtazapine and modafinil with treatment as usual. J. Subst. Abuse Treat. 35, 334-342.

Meneses, A. (2007a). Do serotonin(1-7) receptors modulate short and longterm memory? Neurobiol. Learn. Mem. 87, 561-572.

Meneses, A. (2007b). Stimulation of 5-HT1A, 5-HT1B, 5-HT2A/2C, 5HT3 and 5-HT4 receptors or 5-HT uptake inhibition: short- and longterm memory. Behav. Brain Res. 184, 81-90.

Meneses, A., and Hong, E. (1999). 5HT1A receptors modulate the consolidation of learning in normal and cognitively impaired rats. Neurobiol. Learn. Mem. 71, 207-218.

Meneses, A., and Perez-Garcia, G. (2007). 5-HT(1A) receptors and memory. Neurosci. Biobehav. Rev.31, 705-727.

Micheau, J., and Riedel, G. (1999). Protein kinases: which one is the memory molecule? Cell. Mol. Life Sci. 55, 534-548.

Milekic, M. H., Brown, S. D., Castellini, C., and Alberini, C. M. (2006). Persistent disruption of an established morphine conditioned place preference. J. Neurosci. 26, 3010-3020. 
Miller, C. A., and Marshall, J. F. (2005). Molecular substrates for retrieval and reconsolidation of cocaineassociated contextual memory. $\mathrm{Neu}$ ron 47, 873-884.

Morgan, J. I., and Curran, T. (1989). Stimulus-transcription coupling in neurons: role of cellular immediateearly genes. Trends Neurosci. 12, 459-462.

National Research Council. (1996). "Front matter," in Guide for the Care and Use of Laboratory Animals (Washington: National Academies Press), 1.

O’Brien, C. P., Childress, A. R., Ehrman, R., and Robbins, S. J. (1998). Conditioning factors in drug abuse: can they explain compulsion? J. Psychopharmacol. 12, 15-22.

O’Brien, C. P., Childress, A. R., McLellan, A. T., and Ehrman, R. (1992). Classical conditioning in drugdependent humans. Ann. N. Y. Acad. Sci. 654, 400-415.

Olvera-Cortes, M. E., Anguiano-Rodriguez, P., Lopez-Vazquez, M. A., and Alfaro, J. M. (2008). Serotonin/ dopamine interaction in learning. Prog. Brain Res. 172, 567-602.

Pierce, R. C., and Kalivas, P. W. (1997). A circuitry model of the expression of behavioral sensitization to amphetamine-like psychostimulants. Brain Res. Rev. 25, 192-216.

Quevedo, J., Vianna, M. R., Martins, M. R., Barichello, T., Medina, J. H., Roesler, R., and Izquierdo, I. (2004). Protein synthesis, PKA, and MAP kinase are differentially involved in short- and long-term memory in rats. Behav. Brain Res. 154, 339-343.

Rademacher, D. J., Kovacs, B., Shen, F., Napier, T. C., and Meredith, G. E. (2006). The neural substrates of amphetamine conditioned place preference: implications for the formation of conditioned stimulusreward associations. Eur. J. Neurosci. 24, 2089-2097.

Rafeyan, R., and Napier, T. C. (2008) Clinical evidence for the utility of mirtazapine for relapse prevention in humans dependent upon stimulants and/or opiates. Abstr. Soc. Neurosci. 34, 661.1.

Rebec, G. V., and Sun, W. (2005). Neuronal substrates of relapse to cocaine-seeking behavior: role of prefrontal cortex. J. Exp. Anal. Behav. 84, 653-666.

Rhodes, J. S., Ryabinin, A. E., and Crabbe, J. C. (2005). Patterns of brain activation associated with contextual conditioning to methamphetamine in mice. Behav. Neurosci. 119, 759-771.

Sagar, S. M., Sharp, F. R., and Curran, T. (1988). Expression of c-fos protein in brain: metabolic mapping at the cellular level. Science 240, 1328-1331.

Sax, K. W., and Strakowski, S. M. (2001). Behavioral sensitization in humans. J. Addict. Dis. 20, 55-65.

Schoeffter, P., and Hoyer, D. (1988). Centrally acting hypotensive agents with affinity for 5-HT1A binding sites inhibit forskolin-stimulated adenylate cyclase activity in calf hippocampus. Br. J. Pharmacol. 95, 975-985.

Shen, F., Meredith, G. E., and Napier, T. C. (2006). Amphetamine-induced place preference and conditioned motor sensitization requires activation of tyrosine kinase receptors in the hippocampus. J. Neurosci. 26, 11041-11051.

Shoptaw, S. J., Kao, U., Heinzerling, K., and Ling, W. (2009). Treatment for amphetamine withdrawal. Cochrane Database Syst. Rev. 15, CD003021.

Tronson, N. C., and Taylor, J. R. (2007). Molecular mechanisms of memory reconsolidation. Nat. Rev. Neurosci. 8, 262-275.

Tzschentke, T. M. (1998). Measuring reward with the conditioned place preference paradigm: a comprehensive review of drug effects, recent progress and new issues. Prog. Neurobiol. 56, 613-672.

Tzschentke, T. M. (2007). Measuring reward with the conditioned place preference (CPP) paradigm: update of the last decade. Addict. Biol. 12, 227-462.

Valjent, E., Corbille, A. G., BertranGonzalez, J., Herve, D., and Girault, J. A. (2006). Inhibition of ERK pathway or protein synthesis during reexposure to drugs of abuse erases previously learned place preference. Proc. Natl. Acad. Sci. U.S.A. 103 2932-2937.

Vianna, M. R., Izquierdo, L. A., Barros, D. M., Ardenghi, P., Pereira, P., Rodrigues, C., Moletta, B., Medina, J. H., and Izquierdo, I. (2000). Differential role of hippocampal cAMP-dependent protein kinase in short- and longterm memory. Neurochem. Res. 25 , 621-626.

Voigt, R. M., Herrold, A. A., and Napier T. C. (2011a). Baclofen facilitates the extinction of methamphetamineinduced conditioned place preference in rats. Behav. Neurosci. 125 261-267.

Voigt, R. M., Mickiewicz, A. L., and Napier, T. C. (2011b). Repeated mirtazapine nullifies the maintenance of previously established methamphetamine-induced conditioned place preference in rats. Behav. Brain Res. 225, 91-96.

Voigt, R. M., and Napier, T. C. (2007). Systemic baclofen blocks the expression of methamphetamine-induced conditioned place preference: implications for GABAB receptors in the medial dorsal thalamus. Abstr. Soc. Neurosci. 33, 916.16.

Zlomuzica, A., Ruocco, L. A., Sadile, A. G., Huston, J. P., and Dere, E. (2009). Histamine H1 receptor knockout mice exhibit impaired spatial memory in the eight-arm radial maze. Br. J. Pharmacol. 157, 86-91.

Zombeck, J. A., Chen, G. T., Johnson, Z. V., Rosenberg, D. M., Craig, A. B., and Rhodes, J. S. (2008). Neuroanatomical specificity of conditioned responses to cocaine versus food in mice. Physiol. Behav. 93, 637-650.

Zueco Perez, P. L. (2002). Mirtazapine in the treatment of cocainedependence in patients with methadone. Actas Esp. Psiquiatr. 30, 337-342.

Conflict of Interest Statement: The authors declare that the research was conducted in the absence of any commercial or financial relationships that could be construed as a potential conflict of interest.

Received: 15 October 2011; accepted: 27 December 2011; published online: 13 January 2012.

Citation: Voigt RM and Napier TC (2012) Context-dependent effects of a single administration of mirtazapine on the expression of methamphetamineinduced conditioned place preference. Front. Behav. Neurosci. 5:92. doi: 10.3389/fnbeh.2011.00092

Copyright (๑) 2012 Voigt and Napier. This is an open-access article distributed under the terms of the Creative Commons Attribution Non Commercial License, which permits non-commercial use, distribution, and reproduction in other forums, provided the original authors and source are credited. 